\title{
HYSTERIA IN ONE OF A PAIR OF IDENTICAL TWINS
}

\author{
BY
}

\author{
J. H. PATERSON
}

\author{
From the National Hospital, Queen Square, London
}

\section{Introduction}

Although there exist in the literature a large number of papers of a psychological nature dealing with twins, most of these have been reports on single pairs of twins which, as Luxenburger (1930a) has shown, are largely useless for statistical purposes. Granted that monozygotic, identical twins (as opposed to dizygotic twins) have the same hereditary equipment, an assumption which is now considered

- to be fully justified in practice if not in theory, it is clearly necessary to compare suitable series of monozygotic and dizygotic twins in attempting to assess the relative importance of inherited and environmental factors responsible for psychological disorder such as hysteria. Furthermore, as Slater (1938) has pointed out, it is essential to take care that in any such series the numbers of the two types of twins are comparable with their proportional representation in nature. In this connexion the table compiled from the literature prior to 1930 by Luxenburger (1930b) is interesting, for of the nine pairs of twins showing a psychopathic personality and hysteria described, all were uniovular and none binovular-a state of affairs which militates against their being of much statistical value.

This report, then, cannot be regarded as a contribution to the solution of the problem of the relative importance of environment and heredity in the causation of hysterical.illness. Nevertheless pairs of discordant uniovular twins are of exceptionál significance in elucidating the nature of pathogenic factors of an environmental kind; the parallel history of an individual of like constitution who has remained well provides a chance of putting one's finger on those experiences in the life of the patient which have proved critical in the development of the illness. Part of the interest of the case described below is the suggestion it provides that the twin situation itself may play this role.

\section{Case History of the Twins}

Family History. - The father of the twins is a nervous, irritable man of fifty-three. Before his marriage he is said to have been "shell-shocked" in France, and his wife recalls that in the early days of their marriage he frequently cried like a woman and hid at the bottom of the bed when frightened or distressed. He is at present employed as a jobbing gardener. The twins' nother, who married their father thirty-one years ago, is a stable, $\stackrel{\vec{P}}{+}$ hard-working woman who adopts a sensible attitude to 0 her children and to her husband. She has been married ${ }_{0}$ twice ; by her first marriage she had two children, who $\frac{\bar{\sigma}}{\bar{N}}$ are now thirty-five and thirty-three years old, and by her present husband she has had nine children, all of $\stackrel{\complement}{\varrho}$ whom are living.

The twins then have a stepbrother and sister, an elder क sister of twenty-seven years of age, two younger brothers $\overrightarrow{0}$ and four younger sisters ranging in age from twenty-five to fourteen. Of these, only one brother, now twenty- $\overrightarrow{\vec{\omega}}$ two, is described as being in any way nervous. This ${ }_{\mathscr{N}}$ youth as a child was forbidden to play games on account of a supposedly weak heart ; nevertheless, he was called up into the infantry and served overseas until he was? invalided home on psychiatric grounds. He broke down $\vec{N}$ after witnessing a harrowing massacre of civilians i subsequently he was apparently " unable to walk" and frequently burst into tears. $\mathrm{He}$ is now in regulas $\partial$ employment as a storeman, has married, and is apparent much less nervous than hitherto.

The only family history obtained of other multipe pregnancies is that of a paternal uncle, who has twi sons ; it is not known whether they bear a close reseng blance to each other.

Personal History of the Twins.-Anne and Betty we born twenty-six years ago, Betty being stronger at birth than Anne, who is the subject of this report. Betty, who then weighed $3 \mathrm{lb}$. more than Anne was breast-fed because she made more of an effort to get milk in contradistinction to Anne, who was reared on the bottle. Nevertheless both apparently were well in infancy and childhood, and grew up to be strong, $\odot$ healthy girls. Both twins were backward at school, $\vec{F}$ and the educational authorities at one time suggested $\overrightarrow{0}$ sending them to a special school, although their mother 3 would not countenance this step. They were both good $\supset$ at handiwork, embroidery, toy-making, and the like, but on her own admission Anne was scarcely able to read properly on leaving school at fourteen.

The twins were very much attached to each other, and were apparently inseparable until they left school. Both until then had the same interests and pursuits, and needed no other friends. Nevertheless, Betty was always the pet twin with her family, and it was she who usually took the initiative in organizing their games. When they reached their fourteenth year, however, Betty began to show considerable interest in the opposite sex, to Anne's displeasure, for she tried to prevent her $\frac{T}{O}$ sister from selecting a boy friend at this time, telling her that she did not need any friends other than herself; she was, however, unsuccessful in the attempt. Anne, unlike Betty, showed little interest in boys, and devoted much of her spare time to gardening, tending pet animals, and joining in Girl Guide activities. 
After they left school, both twins went to work for a year in a laundry, working side by side. They both left on the same day after Anne had found the work too arduous, and sought domestic employment, finding work in neighbouring houses. Both continued in this work until they were sixteen years old.

History of Anne's Illness.-At the age of sixteen, Anne was taken ill with jaundice whilst at a summer Rangers' camp. She was sent home, and although her icterus cleared fairly quickly, she apparently had marked anorexia for some seven weeks. She then returned to her domestic duties, although for the next three or four months she felt continuously ill and drowsy, even falling asleep at the meal table. Her drowsiness increased, and at length she was admitted to hospital (some nine years ago) complaining in addition of backache and pains in her limbs. The hospital records state that although apyrexial on admission, she was very drowsy, especially in the daytime ; she was noted to have sluggish pupillary reactions to light, and exaggerated knee jerks, whilst an ophthalmologist reported low-grade bilateral optic neuritis. A lumbar puncture revealed a normal cerebrospinal fluid save for the presence of 8 cells per c.mm., their nature not being specified, and $50 \mathrm{mg}$. of protein per $100 \mathrm{c.cm}$. She was diagnosed as having acute encephalitis lethargica and was transferred after five weeks to an Isolation hospital where she was detained for a further five months.

Within a few months Anne developed marked weakness of her left arm and leg, whilst both hands became very shaky and tremulous. On one occasion, following a hearty slap on the back (administered probably in reproof) she is said to have lost consciousness suddenly and to have remained in this state for a considerable time. Subsequently she developed occasional spasms of her back with jerking movements of her left leg when she attempted to walk. It was also noticed that any sudden noise or start might precipitate a screaming and crying bout. Subsequently she was transferred to a third hospital, where she was treated as an in patient for a further eighteen months. Despite intensive physiotherapy she made little progress, until one day when the power suddenly returned to her limbs in a matter of a very few minutes. She was then discharged home; the diagnosis on discharge being "psychoneurosis with functional paralysis of the legs." Her mother recalls that at this time she was able to get about fairly well except for slight weakness in her arms and legs. At this time too, she started to wear masculine dress and to crop her hair short; in explanation, Anne said that she wore trousers to cover her thin legs and kept her hair short as she had difficulty in lifting her arms to dress her own hair.

Soon after Anne's return home, the family was evacuated to the west country, and whilst there Anne had a relapse. She was then supplied with special corsets and a caliper for her left leg; these she wore until four years ago, when they were given up on the advice of an orthopædic specialist. By this time her family had returned to their own home, so she was able to attend her local hospital where she was given regular physiotherapy. Her condition improved slowly and though she had temporary relapses from time to time she was able to get about fairly well until four months before admission to this hospital, when, on hearing of the sudden death of a friend, she became suddenly unable to walk once more and took to her bed for a while. Latterly she has been hobbling about with the aid of two sticks. She has also complained of numerous attacks of faintness and loss of consciousness over the last two years, although her practitioner who has seen her in such attacks was not convinced that they were organic in nature.

During the last nine years the patient has not been in regular employment ; from time to time she has made a little money by breeding rabbits and selling plants. Her mother has stated that although she frequently expressed her desire to become independent of family support, whenever regular work was suggested she stated that she did not want to take up anything if she was not going to be able to carry on. Her interests and hobbies have continued to be largely concerned with gardening, the keeping of pets, and the Girl Guides; to date she has apparently taken little interest in men.

Betty's Past History.-When Anne was taken ill at sixteen, her sister gave up domestic work and took employment as a waitress. At this age she first became engaged to a youth although she broke off the engagement on her own account. Soon afterwards she met her present husband, marrying him when eighteen. She gave up her work some six weeks before the wedding, as she felt run down, had lost her appetite, and complained of frequent headaches with insomnia. However, she apparently recovered her health before the wedding day and remained well until about three months before examination. Since then she has felt tired and run down, and has lost weight, but it appears that she is keeping house for her husband and six-year old daughter in difficult circumstances. She has carried on with her duties, however, and has not broken down at any time since her marriage.

Findings on Examination.-Anne, on admission to the National Hospital, Queen Square, in November, 1947, was found to be a rather thin but well-proportioned girl, who presented herself in masculine clothes, wearing a shirt and tie, long trousers, and sports jacket ; her hair was cut short and brushed in a male style. Her performance on simple initial intelligence tests suggested a low level of intelligence, but in addition her answers strongly suggested an hysterical attitude to the tests; thus a characteristic answer was, "I don't seem to get on with that-I go all blanky." She appeared to be somewhat shy, depressed, and apathetic, but she was quite co-operative and well behaved.

Physical examination revealed no abnormality whatever in her general systems or in her central nervous system, and although her lower limbs were seemingly very weak no wasting or alteration in tone was demonstrable, whilst all the muscle groups involved contracted vigorously as antagonists and synergists. Her gait was frankly hysterical, and although she seemed unable to walk without the support of two sticks, when these were removed she was able to avoid hurting herself when she fell.

Ancillary investigations gave negative findings; thus no radiological abnormality was detected in her chest, lumbar spine, pelvis, or skull ; an electro-encephalogram and a glucose tolerance curve were likewise normal.

Betty on the other hand looked in fair health. On examination no physical abnormalities were detected.

A Comparison of Physical Features.-A comparison of the physical features of the twins revealed a distinct difference in general appearance, although no doubt could be entertained but that they are identical twins. Betty, a healthy young woman of feminine build and appearance, was well developed ; she was 63 inches in height and weighed $8 \mathrm{st} .7 \mathrm{lb}$. Anne, on the other hand, 
TABLE I

ANALYSIS, OF FINGER PRINTS OF TWINS

\begin{tabular}{l|l|c|c|c|c|c}
\hline Fingers : & & 1 & 2 & 3 & 4 & 5 \\
\hline \multirow{2}{*}{ Anne } & R. & UL. 13.0 & W. 21.20 & W. 18.25 & W. 23.16 & UL. 19.0 \\
& L. & UL. 17.0 & W. 15.19 & DL. 15.10 & W. 21.14 & UL. 19.0 \\
\hline \multirow{2}{*}{ Betty } & R. & UL. 16.0 & W. $16 \cdot 22$ & W. 19.25 & W. 28.20 & UL. 16.0 \\
& L. & DL. 14.3 & W. 14.17 & DL. 21.18 & W. 24.20 & UL. 19.0 \\
\hline
\end{tabular}

looked definitely more masculine ; her face was thinner, her hips narrower, and she maintained a slightly kyphotic stance in comparison with her healthy twin's more upright posture. She was three inches shorter, and weighed $17 \frac{1}{2} \mathrm{lb}$. less than Betty. Nevertheless in regard to the texture and colour of their hair, eyelashes, and eyebrows, the colour of their eyes and the iris pattern, and also the shape of the ears, mouths, and hands, a striking similarity obtained. Apart from the difference in build and appearance noted above, no points of discrepancy of any degree were found.

Their blood groups were both Group O, Rh-positive, whilst their electro-encephalographic report was, " $\mathrm{Re}$ cords made on these patients were normal and identical, showing a symmetrical alpha rhythm of ten a second." In addition they both gave similar responses to the phenylthiocarbamide test for taste and smell.

Finally, a comparison of their finger prints showed the pattern types and ridge counts (counts to radial triradius given first ; $\mathrm{W}=$ whorl ; $\mathrm{DL}=$ double loop ; $\mathrm{UL}=$ ulnar loop) given in Table I. The prints show a closer similarity between the twins than between their right and left sides. The Anne-Betty product-moment correlation coefficient is +0.86 ; the right-left correlation coefficient is +0.80 .

Intellectual Capacity.-A comparison of the intellectual capacity of the twins, tested on a variety of intellectual tests, gave the results in Table II. It will be seen from

TABLE II

COMPARISON OF INTELLIGENCE TESTS ON THE TWINS

\begin{tabular}{l|c|c}
\hline \multicolumn{1}{c|}{ Test } & Anne & Betty \\
\hline $\begin{array}{l}\text { Wechsler Bellevue :: } \\
\text { Verbal I.Q. }\end{array}$ & 78 & 86 \\
Performance I.Q. & 92 & 102 \\
I.Q. Whale Test & 83 & 93 \\
$\begin{array}{l}\text { Matrices : } \\
\text { Score }\end{array}$ & 28 & 23 \\
Percentile & 10 th & 5 th \\
Grade $:$ & JV & V \\
$\begin{array}{l}\text { Koh's Blocks : } \\
\text { Score }\end{array}$ & 72 & 78 \\
Mental Age & $13 \cdot 9$ & $14 \cdot 2$ \\
Category \\
$\quad$ Benton's Scale) & High average & High average \\
Reading and Spelling & & \\
$\quad$ Age : & 6 years & $6 \frac{1}{2}$ years \\
\hline
\end{tabular}

the above results that performance test scores were superior to verbal; tests involving school-learning in particular were but poorly performed. Both twins were clearly below normal intelligence, but they did not sink into the category of mental defectives ; Betty's performance was slightly better than Anne's in most of the tests, but, despite individual variations, in no test did their scores differ by more than 10 per cent.

In view of Anne's assumption of male attire both twins were tested on the selective vocabulary test devised by Slater (1944). Anne scored successes with five masculine and seven feminine words, falling into the ninety-second percentile for women and showing a shift towards the male side. Betty did better, falling into the seventy-fifth percentile with six masculine and thirteen feminine words, but even this result is a little towards the male side. It is interesting to note that both sisters showed a remarkable resemblance with some attempts at definition. Thus, both women thought that the word "dragoon" had something to do with Africa, that $\vec{N}$ "dovetail" was a bird, and that "kerosene" was it seed.

After preliminary investigation in this hospital, Ann 8 was treated with intensive daily physiotherapy, whilst she also attended Dr. Debenham regularly for psycho therapy. As a result she made slow but steady improve ment and on her discharge home after two months in hospital, she was walking well without the aid of support: in addition she had ceased to show the short periods of hysterical mutism and "faints" which were a feature her past history and which were in evidence on admission? She has been seen on several occasions since she left hospital and her condition has not noticeably changed.

\section{Discussion}

It was very evident that when admitted to this hospital Anne was a pure hysteric, no evidence of any underlying organic disorder being found. However, it can hardly be doubted that the attack of infective hepatitis she sustained ten years ago might well have rendered her physically ill for several months and might have accounted in some measure for her curious state on admission to hospital nine years ago. Nevértheless within a few months she had developed symptoms which seem to have been largely functional in nature, anticipating the development of a florid hysterical state. In passing one might mention that although detailed information is not available on this point, it now seems hardly likely that she was suffering from acute encephalitis lethargica when admitted to hospital at the age of sixteen, although the true o nature of her disease at that time is not now $N$ apparent.

Our subject then developed overt hysterical

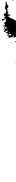


symptoms some time after sustaining an infection constituting a definite physical handicap, which, operating over several months, prevented her from enjoying many activities in her twin sister's company. It should be recalled, too, that this took place at a time when Betty had already started to seek the company of the opposite sex, breaking away from their previously exclusive twin friendship, a rift which Anne had unavailingly attempted to prevent. Furthermore, it seems that Anne, the smaller and weaker twin at birth, had always been more dependent on her sister, for it was Betty, the family favourite, who usually took the initiative. In this way a situation developed which might well have precipitated Anne's hysterical breakdown. A somewhat similar state of affairs was described by Newell (1930), in which one of a pair of identical twins reared together acquired an acute infection (thought to have been either acute poliomyelitis or an acute encephalitis) at the age of two, following which her physical development was retarded. When the twins were examined at fourteen years of age, the affected twin was found to be a highly strung, nervous girl, who felt herself to be, and indeed was, physically, intellectually, and socially inferior to her twin, of whom she had become inordinately jealous. Newell concluded that these psychological differences were more likely due to the handicap provided by physical disease than to any inherited difference or to environmental factors common to the twins.

An interesting feature shown by the case under discussion was that Anne preferred to wear masculine attire, although it is of note that even when she discarded such clothes she had a more masculine build and appearance than her twin. This difference between the two sisters was supported in some measure by their responses to Slater's selective vocabulary test, and, as noted above, Anne in her answers showed more of a shift to the male side than did her healthy twin. Her mother states that she first began to wear male attire when she left hospital seven years before, and that she maintained in explanation that trousers concealed the thinness of her lower limbs and that a masculine hair style was easier for one in her enfeebled state to manage.

It is perhaps not too fanciful to suppose, however, that her liking for male clothing was in part motivated by a subconscious desire to maintain Betty's exclusive companionship at a time when she had not herself developed the heterosexual proclivities shown by her healthy twin.

That identical twins may show marked differences in psychosexual development even when brought up together has been noted before, and Cronin (1933) in an extensive psychoanalytical study described such a pair, although his conclusions are not germane to our study and need not therefore be discussed.

When identical twins are brought up together and come under the same environmental influences at the same time, they will naturally grow more alike than they otherwise might be, and one might reasonably expect them to show by and large the same personality responses to any given situation. However, as Lange (1929) has shown, they may in fact develop in a polar direction - the one, for example, vain and unscrupulous, the other shy and conscience-stricken. He postulates that this may be due to a tendency for them to regard their qualities and faults as common possessions. Our pair, though strikingly similar in physical build and intellectual capacity, showed some evidence of this polarity. Thus Anne, is shy, retiring, overdependent, and immature in her psychosexual development, whilst Betty is much more enterprising and self-reliant and at a normal age she sought to break away from her sister's exclusive company in favour of that of the opposite sex.

When an attempt is made to determine the cause of Anne's hysterical breakdown, it should be borne in mind that inherited factors are probably of considerable importance, as it will be recalled that both her father and one of her brothers have shown evidence of an unstable personality. Indeed,' her healthy twin, though never having shown overt hysteria as far as is known, had to give up her work six weeks before her marriage on account of symptoms which had no apparent physical basis.

The problem presented by this pair of twins is, then, given that both are equally endowed by heredity with a hysterical potentiality, how it is that one of them has had a fairly normal career, with only a few weeks during which she showed a mild neurasthenic syndrome, while the other has suffered a chronic and almost completely incapacitating illness of nine years' duration, during which she has lived a dependent and parasitic life confined to her own home. We must suppose that the twins took a slightly different path very early in life. Owing to the fact that uniovular twins commonly share the same placental circulation, if either has a slight advantage over the other, that advantage is likely to become exaggerated. There are on the average greater differences in birth weight between uniovular than between binovular twins. Betty was born rather heavier than Anne and was more robust; as a consequence she was given the additional advantage of breast-feeding, of which Anne was deprived. We may suppose that Anne never caught up with her sister's lead, and as a result became more dependent on Betty than Betty 
was on her. This again may well have led to the family's preferring Betty to Anne who accordingly took more and more a back seat.

The illness that Anne underwent at sixteen was probably of critical significance, and we must attribute to it the eventual considerable difference in physique between the twins. It may perhaps also have partly caused the greater retardation of development in intelligence in Anne's case. The slight difference between the twins also became critical in the psychosexual field. When Betty started to take a normal interest in the opposite sex at 14, Anne did not follow her lead but took the attitude of the rejected lover. According to Dr. Debenham, who undertook some psychotherapy for Anne and also had a number of interviews with Betty, both twins show some homosexual features in the psychological field, but in Anne's case they are more marked. Anne's development took an overtly homosexual form, as is shown by the style of dress she assumed, although it is not suggested that she has at any time engaged in homosexual practices.

Taking the illness from the psychodynamic point of view, we may say that Anne's hysteria was a true flight into illness when she found that, do what she्己 could, she could no longer retain her old place in her twin's affections. This excessive attachment common among uniovular twins but very rare्e between ordinary sibs or binovular twins, seems to have played a dominant role in the course of Anne's long illness; ; if she had not been born a twin shep might never have become an hysteric.

I wish to express my thanks to Dr. Margaret Fergusotr. for her psychometric assessment of the twins, to $\mathrm{Dr}=$ Debenham and to Dr. Elithorne for taking and comparing? their finger prints. I am especially grateful to Dr. Eliots Slater for his help and encouragement in the preparationof this report. In addition, I have to thank the Medica Committee of the National Hospital for their permission to publish this case.

\section{REFERENCES}

Cronin, H. J. (1933). Psychoanal. Rev., 20, 375.

Lange, J. (1929). Allg. Z. Psychiat., 90, 122.

Luxenburger, H. (1930a). Fortscht. Neurol. Psychiat. $2,373$.

(1930b). Zbl. ges. Neurol. Psychiat., 56, 145.

Newell, H. W. (1930). Amer. J. Orthopsychiat., 1, 61.

Slater, E. T. O. (1938). J. Neurol. Psychiat., n.s. 1, $239 \overrightarrow{\mathrm{N}}$

Slater, P. (1944). "Selective Vocabulary Testo London.

\section{BOOK REVIEWS}

Studies from the Rockefeller Institute for Medical Research, Volumes 131 and 132. A Study of Nerve Physiology. By Rafael Lorente de Nó. 1947 : Rockefeller Institute for Medical Research, New York. Pp. 496 and 548 . Price $\$ 2$ each volume.

This monumental work marks yet another milestone in the rapidly evolving history of neurophysiology. Following his early contributions to neuro-anatomy, Rafael Lorente de Nó turned his attention to the detailed structure of the nervous system and produced his studies of the cyto-architecture of the cerebral cortex. This consideration of structure led him to investigate nerve cells functioning in groups, from which evolved his concepts of neuronal circuits and reverberatory systems recently developed by others into the theory of "feed-back" and " oscillator systems."

Finally, Lorente de Nó's enquiries narrowed down to the functions of neurones as individuals : and these two volumes embody the results of this work. Filled with details of hundreds of personal experiments, they also record the observations of nearly every student of neuronal function.

Firstly, a consideration of the effect of changes in the external environment upon the function of individual nerve fibres leads to important conclusions regarding the role of ionic balance and gaseous exchange in this function. Then follows a series of studies on the electrical properties of nerve, posed agains the physicochemical background of the earlier chapters. These experiments were carried out on isolated frog nerve preparations, most of the studies consisting of the measurement of the changes in demarcation potentials under varying physical and chemical conditions. Par. ticular stress is laid on the properties of nerve fibres" considered as core conductors, and upon polarization of nerve fibres, factors which have previously been given scant attention. From these results the author $\overrightarrow{\overrightarrow{0}}$ in collaboration with Dr. L. Davis, proceeds to as mathematical analysis of his findings and the formulationof the properties of nerve in mathematical terms. This is of importance in forming an interesting corollary to. the studies of workers such as Rachevsky, McCulloch, and Pitts.

The question of the role of acetycholine in nerve function is discussed at length. A nice balance is maintained between the rival schools of thought, the views of both Nachmansohn and his colleagues on the one hand, and of Gerard and of Eccles on the other being presented against the background of Lorente deo No's own fundamental experiments. But the principab theme of these volumes is the mutual interrelation which exists between intracellular metabolism on the one hand, and the electrical expression of that metabolism on the other : the studies detailed in this work bring us closero to an understanding of the causal relations between these two aspects of neuronal activity.

However, there are certain adverse features which, $N$ to the ordinary reader, will present great obstacles to 